recorded in the plant kingdom, the previous highest being that recorded by Mantón ${ }^{3}$ for Ophioglossum vulgatum $(n=250-260)$.

Department of Botany, G. C. K ING Queen Mary College

(University of London), Mile End Road, London, E.1. May 4.

- King, G. C., Nature, 171, 181 (1953).

${ }^{2}$ See Breiger, W., "Die Desmidiaceen-Rabenhorst KryptogamenFlora", 13 .

Manton, I., "Problems of Cytology and Evolution in the Pteridophyta" (Cambridge, 1950).

\section{Relation between Dye Uptake and Cytoplasmic Streaming in Amøba proteus}

GOLDACRE ${ }^{1}$ has recently proposed a theory of osmotic work which is based, in part, on the manner in which streaming amcbæ accumulate vital dyes. Goldacre reported that streaming Amœeba discoides, when placed in dilute solutions of neutral red, methylene blue, or brilliant green, accumulated the dye in the tail. Non-streaming amoebre became stained only at the periphery. The experiments were repeated in this laboratory using Amceba proteus. The observations in general confirmed those reported by Goldacre, and further experiments employing hydrostatic pressure lend support to his interpretation.

Neutral red ( 0.005 per cent solution) and methylene blue $(0.010$ per cent solution) appeared first in the tail of streaming $A$. proteus; but in each case the dye was soon distributed throughout the cytoplasm in small vacuoles which eventually became coloured intensely red or blue. After $48 \mathrm{hr}$. in neutral red solution, the cytoplasm had a general pink tinge colour in addition to the intense accumulation of dye in the small vacuoles. The nucleus remained unstained. The amobæe seen with the naked eye stand out as bright red spots. In a 0.002 per cent solution of brilliant green, amœbæ immediately ceased streaming and within a few hours underwent cytolysis.

The effect could be emphasized even more if amœbre were kept at $12^{\circ} \mathrm{C}$. for some hours. At such a low temperature most of the amœebæ became monopodal in form and streamed very weakly. Brought to room temperature $\left(22^{\circ} \mathrm{C}\right.$.) in 0.005 per cent neutral red solution over a period of 3-4 min., the amcebr began streaming more rapidly than controls and with a very marked accumulation of dye in the tail. The dye was soon distributed throughout the amobre by the moving plasmasol. Once the dye has been distributed, the colour contrast is insufficient to allow detection of any slightly higher concentration of dye in the tail.

If the dye uptake is causally related to streaming, amobæ subjected to hydrostatic pressure sufficient to prevent streaming should also fail to accumulate dye. Amœebæ were placed in a 0.005 per cent neutral red solution and kept under a pressure of 425 atmospheres for $30 \mathrm{~min}$. With this treatment the amokire rounded up, and the surface membrane could be distinguished as a blurred red line (in optical cross-section). No dye was detectable in the cytoplasm. The amobæ thus treated did not resume streaming until 30-60 min. after release of the pressure. A second group of amœbse was placed in
0.005 per cent neutral red solution and subjected to a pressure of 350 atmospheres for $30 \mathrm{~min}$. Again the amœbæ rounded up, with a visible accumulation of dye on the surface; but within 60 sec. after release of the pressure they began streaming even more vigorously than the controls. When the amobæ had moved a distance equal to but a fraction of their lengths, the surface membrane was no longer visibly 'stained', and dye was now clearly visible in the tail. With continued streaming the dye could be seen to be carried forward and distributed throughout the cytoplasm by the plasmasol.

The pressure experiment is of particular interest because it not only relates the dye uptake to visible streaming but also to unfolding of protein molecules, according to Eyring, Johnson and Gensler's interpretation of pressure effects on proteins 2 .

In neutral red staining it was noticed that the tail of the amoba was slightly acid relative to the rest of the cytoplasm.

Finally, it should be emphasized that the observation of the accumulation of dye at the tail requires considerable time and patience; the effect will not be detected by the casual observer.

I wish to thank Dr. Daniel Mazia for his direction of this work.

Department of Zoology,

D. M. Prescott

University of California,

Berkeley, California. March 28.

' Goldacre, R. J., Int. Rev. Cut., 1, 135 (1952). Goldacre, R. J., and Lorch, I. J., Nature, i66, 497 (1950). ${ }^{2}$ Eyring, H., Johnson, F., and Gensler, R., J. Phys. Chem., 50, 453

Prescott's confirmation and extension of the results of Lorch and myself suggest the following comments :

(1) While the accumulation of neutral red in the tail of the amceba must often have been overlooked by the casual observer, it can readily be made visible by sucking away most of the dye solution in the hanging drop with a fine pipette, which improves the contrast. Better still, if the streaming of the amoeba is inhibited by too high a concentration of dye, it can be restored by replacing the dye solution with culture medium, when the dye which has been adsorbed by the cortical gel over the whole surface of the amoba is completely released into the tail when the amcba has moved a distance equal to its own length.

Prof. J. F. Danielli informs me that students at King's College, London, have now regularly seen this phenomenon in a class experiment using $A$. proteus, which we have found behaves similarly to $A$. discoides in this respect.

(2) The slight acidity in the tail of the amœba reported by Prescott has sometimes been suggested as the cause of the accumulation of the partly ionized dye. Mere passive diffusion of the un-ionized molecular species through the membrane, to ionize again inside according to its ionization constant and the $p \mathrm{H}$, would result in a higher concentration of the dye ion in the more acid region at equilibrium. However, experiment suggests that this difference in colour of the indicator between the tail and the cortical gel is not necessarily due to a change in $p \mathrm{H}$, but to a change in the protein error of the indicator when the protein molecules fold up. It was found that when serum albumin, in a solution strongly buffered at $p \mathrm{H} 7$ and containing a trace of indicator, was heated 